\title{
Perceived Stress as Predictor of Psychological Well-being among
}

\section{Indian Youth}

\author{
Kalpna Anand ${ }^{1}$, Y K Nagle ${ }^{2}$
}

\section{ABSTRACT}

College is a time of varied experiences and expectations wherein students are striving to give a direction to their life and make a career for themselves. Unemployment, fierce competition and insecurity are some of the many problems that the youth of India faces everyday which culminate into stress and has the potential to affect psychological health. Thus, the present study seeks to explore perceived stress and psychological wellbeing among college students and their interrelationship. A total of 281 college students (Males=174, Females=107) in the age range of 18-24 years, participated in the study. They were administered Perceived Stress Scale and Ryff's Scale of Psychological Wellbeing. Results revealed that perceived stress had significant negative relation with all the six dimensions of psychological wellbeing. Perceived Stress accounted for a large variance in all the dimensions of psychological wellbeing. Perceived Stress came out to be one of the major contributors to psychological health and wellbeing.

Keywords: Psychological Wellbeing, Perceived Stress, College Students, Gender Difference

The National Youth Policy of India (2014) defines the youth population as those in the age group of 15-29 yr which comprises almost one third of the total population. Lazarus and Folkman (1984) defined stress as "involving a particular relationship between the person and the environment that is appraised by the person as taxing or exceeding his or her resources and endangering his or her well being” (p. 19). College students are a unique group of individuals who face specific intrapersonal, interpersonal, environmental, and academic stressors (Ross, Niebling, \& Heckert, 1999). Many of these stressors may not necessarily be pertinent to other population groups (Ross, Niebling, \& Heckert, 1999; Misra \& McKean, 2000; Camatta \& Nagoshi, 1995; Kadison \& DiGeronimo, 2004). It is a critical phase of life and a period of major physical, physiological, psychological, and behavioural changes. Indian youth is currently facing a host of social problems like, unemployment, fierce competition, and rapid social change to

\footnotetext{
${ }^{1}$ Scientist ' $D$ ', Institute of Aerospace Medicine, IAF, Bangalore, India

${ }^{2}$ Scientist 'F' Defence Institute of Psychological Research, DRDO, Delhi, India

*Responding Author

(C) 2016, K Anand, Y Nagle; licensee IJIP. This is an Open Access Research distributed under the terms of the Creative Commons Attribution License (http://creativecommons.org/licenses/by/2.0), which permits unrestricted use, distribution, and reproduction in any Medium, provided the original work is properly cited.
} 


\section{Perceived Stress as Predictor of Psychological Well-being among Indian Youth}

name a few. The structure of a typical Indian family is changing and the bond once shared by parents and children is weakening with time. Students often need to adjust to a new social environment, being away from home, dealing with living away from parental authority, and increased academic challenges (Towbes \& Cohen, 1996).

Psychological Wellbeing is the dynamic and active process that gives a sense of knowledge to the people about how their lives are enduring the interaction between their circumstances, activities and psychological resources or 'mental capital'. "It is about lives going well. It is the combination of feeling good and functioning effectively." (Huppert, 2009). Feelings of wellbeing are vital to the overall health of individuals, enable them to successfully overcome difficulties and achieve what they want out of life. Well-being is associated with multiple health, job and family-related benefits. Individuals with high levels of well-being are considered to be more productive at work and are more likely to add value to their communities.

The current has been taken up to assess the relationship between perceived stress and psychological wellbeing among Indian youth. Perceived stress can influence the way a person evaluate social support available to him/her. It affects both physical and mental health which then translates into a vicious circle wherein events and people around are also perceived in an unfavorable manner. It is important to study how perceived stress influences the psychological wellbeing among youth.

\section{METHODOLOGY}

Sample:

281 college students (Males=174, Females=107) from six states of India participated in the study. Their age ranged from 18- 24 years with a mean of 21.37. 146 of them were attending professional courses (BE, Law, Medicine, etc) while 135 were enrolled in regular courses (BA, BSc, BCom, etc).

\section{Measures:}

The psychometric measures used in the study were self report questionnaires. All scales met or exceeded acceptable standards of psychometric quality. Higher scores for each scale indicates higher levels of the characteristic measured.

Perceived Stress Scale (Cohen, 1983)

It is a measure of the degree to which situations in one's life are appraised as stressful. It assesses the degree to which participants evaluate their lives as being stressful during the past month. It comprises of 14 questions with responses varying from 0 to 4 for each item and ranging from never, almost never, sometimes, fairly often and very often respectively on the basis of their occurrence during one month prior to the survey. The PSS has an internal consistency of 0.85 (Cronbach $\alpha$ co-efficient) and test-retest reliability during a short retest interval (several days) of 0.85 . 


\section{The Ryff's Scales of Psychological Well-Being (Ryff, 1989)}

It has 42 items which consists of six subscales: (a) Positive Relations with Others (PR), SelfAcceptance (SA), Autonomy (AU), Environmental Mastery (EM), Personal Growth (PG) and Purpose in Life (PL) which are to be rated on a 6- point scale that ranges from "strongly disagree" to "strongly agree". Test - retest reliability coefficients range from 0.81 to 0.85 .

\section{Procedure:}

The measures were administered to the participants in a class room setting wherein approximately 20 to 25 students were instructed and their responses were collected. Participants were provided with scales. i.e. Perceived Stress Scale and Ryff's Psychological well being Scale and an average of 30 minutes were taken by them to fill up the questionnaire.

The survey data obtained were analyzed descriptively, zero order correlation and Stepwise Multiple Regression was carried out to infer the perceived stress predictors of psychological wellbeing among Indian Youth.

\section{RESULTS \& DISCUSSION}

Table 1 gives an overview of the scores and standard deviation of perceived role stress and six dimensions of psychological wellbeing.

\begin{tabular}{|l|r|r|r|r|}
\hline \multicolumn{1}{|c|}{ Variables } & \multicolumn{1}{c|}{ Min } & \multicolumn{1}{c|}{ Max } & \multicolumn{1}{c|}{ Mean } & \multicolumn{1}{c|}{ Std. Dev. } \\
\hline Autonomy (AU) & 25.0 & 54.0 & 44.801 & 5.6495 \\
\hline Environmental Mastery (EM) & 28.0 & 54.0 & 40.833 & 5.3282 \\
\hline Personal Growth (PG) & 29.0 & 54.0 & 42.146 & 4.7453 \\
\hline Positive Relations (PR) & 30.0 & 54.0 & 45.737 & 4.4177 \\
\hline Purpose in Life (PL) & 27.0 & 54.0 & 43.637 & 4.7611 \\
\hline Self Acceptance (SA) & 24.0 & 54.0 & 43.046 & 4.9318 \\
\hline Perceived Stress (PSS) & .0 & 29.0 & 11.110 & 5.1338 \\
\hline Age & 18 & 24 & 21.37 & 1.518 \\
\hline
\end{tabular}

Table no. 1 shows that the participants were in the age range of $18-24$ years $(\mathrm{M}=21.37, \mathrm{SD}=$ 1.518) with $90 \%$ of the participants between the age group of 19-23 years. Psychological well being has six dimension, each one's scores ranging from 9-54; positive relations with other ( $M=$ 44.801, $\mathrm{SD}=5.6495)$, autonomy $(\mathrm{M}=40.833, \mathrm{SD}=5.3282)$, environmental mastery $(\mathrm{M}=42.146$, $\mathrm{SD}=4.7453)$, positive growth $(\mathrm{M}=45.737, \mathrm{SD}=4.4177)$, purpose in life $(\mathrm{M}=43.637, \mathrm{SD}=$ 4.7611), self acceptance $(M=43.046, S D=4.9318)$ and overall psychological wellbeing $(M=$ 260.199, $\mathrm{SD}=22.6150$ ) indicating overall above average psychological wellbeing of the participants. The sample had a mean of $11.110(\mathrm{SD}=5.1338)$ on perceived stress which is below average considering the range of $10-40$. The sample had a mean of $11.110(\mathrm{SD}=5.1338)$ on perceived stress which is below average considering the range of 10-40. 
Perceived Stress as Predictor of Psychological Well-being among Indian Youth

Table 2: Showing correlations among the study variables.

\begin{tabular}{|l|l|l|l|l|l|l|l|}
\hline & PR & AU & EM & PG & PL & SA & PSS \\
\hline PR & 1 & $.387^{* *}$ & $.571^{* *}$ & $.527^{* *}$ & $.496^{* *}$ & $.549^{* *}$ & $-.470^{* *}$ \\
\hline AU & $.387^{* *}$ & 1 & $.497^{* *}$ & $.394^{* *}$ & $.417^{* *}$ & $.385^{* *}$ & $-.339^{* *}$ \\
\hline EM & $.571^{* *}$ & $.497^{* *}$ & 1 & $.505^{* *}$ & $.483^{* *}$ & $.588^{* *}$ & $-.573^{* *}$ \\
\hline PG & $.527^{* *}$ & $.394^{* *}$ & $.505^{* *}$ & 1 & $.522^{* *}$ & $.563^{* *}$ & $-.380^{* *}$ \\
\hline PL & $.496^{* *}$ & $.417^{* *}$ & $.483^{* *}$ & $.522^{* *}$ & 1 & $.479^{* *}$ & $-.379^{* *}$ \\
\hline SA & $.549^{* *}$ & $.385^{* *}$ & $.588^{* *}$ & $.563^{* *}$ & $.479^{* *}$ & 1 & $-.482^{* *}$ \\
\hline PSS & $-.470^{* *}$ & $-.339^{* *}$ & $-.573^{* *}$ & $-.380^{* *}$ & $-.379^{* *}$ & $-.482^{* *}$ & 1 \\
\hline
\end{tabular}

** Correlation is significant at the 0.01 level (2-tailed).

* Correlation is significant at the 0.05 level (2-tailed).

Perceived stress is significantly related to all the six dimensions of psychological wellbeing. Stress has come out to be negatively and significantly related to Positive Relation with others ( $\mathrm{r}$ $=-.470, \mathrm{p}<.01)$, Autonomy $(\mathrm{r}=-.339, \mathrm{p}<.01)$, Environmental Mastery $(\mathrm{r}=-.573, \mathrm{p}<.01)$, Personal Growth $(r=-.380, p<.01)$, Purpose in Life $(r=-.379, p<.01)$ and Self Acceptance $(r$ $=-.482, \mathrm{p}<.01)$. Perceived stress and psychological wellbeing have different directions in which they operate, when perceived stress is more it brings down the psychological wellbeing of the individual.

Table 3: Multiple Regression summaries of Psychological Wellbeing (Total)

\begin{tabular}{|l|l|l|l|l|l|}
\hline Model & Predictor & Adj $\mathbf{R}^{\mathbf{2}}$ & $\boldsymbol{\beta}$ & F-value & Significance \\
\hline 1 & P Stress & .330 & -.577 & 139.024 & .000 \\
\hline
\end{tabular}

Perceived Stress accounts for 33\% variance (sig, .000) in overall psychological wellbeing. Since this variance is significant it was thought pertinent to study the variance explained by all the six dimensions individually

Table 4: Multiple Regression summaries of Psychological Wellbeing

\begin{tabular}{|c|c|c|c|c|c|}
\hline Predictor & $\begin{array}{c}\text { Dependent } \\
\text { Variable }\end{array}$ & Adj R & $\boldsymbol{\beta}$ & F-value & Sig \\
\hline \multirow{4}{*}{ P Stress } & PR & .219 & -.470 & 79.317 & .000 \\
\cline { 2 - 6 } & AU & .115 & -.339 & 36.144 & .000 \\
\cline { 2 - 6 } & EM & .326 & -.573 & 136.381 & .000 \\
\cline { 2 - 6 } & PG & .141 & -.380 & 46.984 & .000 \\
\cline { 2 - 6 } & PL & .141 & -.379 & 46.922 & .000 \\
\cline { 2 - 6 } & SA & .229 & -.482 & 84.396 & .000 \\
\hline
\end{tabular}

(c) The International Journal of Indian Psychology, ISSN 2348-5396 (e)| ISSN: 2349-3429 (p) | 214 


\section{Perceived Stress as Predictor of Psychological Well-being among Indian Youth}

Perceived stress accounts for $21.9 \%$ variance (sig, .000) in Positive relation with others dimension of psychological wellbeing. Perceived stress is counterproductive to having and maintaining positive relations with others. Perceived stress accounts for $11.5 \%$ variance (sig, .000) in Autonomy dimension of psychological wellbeing. Perceived stress is negatively related to the experience of Autonomy that shows that higher the score on Perceived stress the lower will be the Autonomy thus working in opposite direction. Perceived stress is counterproductive to psychological well being. Perceived stress accounts for $32.6 \%$ variance (sig, .000) in Environmental mastery dimension of psychological wellbeing. Perceived stress shows largest variance in this dimension emphasizing the importance of perceived stress in the capability to manage the environment and complete the complex array of external activities. Perceived stress accounts for $14.1 \%$ variance (sig, .000) in Personal growth dimension of psychological wellbeing. Perceived stress is negatively related to the experience of personal growth. Perceived stress accounts for $11.5 \%$ variance (sig, .000) in Purpose in life dimension of psychological wellbeing. Perceived stress is negatively related to the this dimension that shows that higher the score on Perceived stress the lower will be the score on PL. Perceived stress accounts for 22.9\% variance (sig, .000) in Self Acceptance dimension of psychological wellbeing. It shows that it becomes difficult to accept self with increase in perceived stress.

Perceived stress shows significant positive relation with all the six dimensions of wellbeing, i.e. Environmental Mastery (EM), Personal Growth (PG), Purpose in Life (PL), Positive Relations (PR), Autonomy (AU) and Self Acceptance (SA). This shows that the perceived stress is counterproductive to the psychological wellbeing. Perceived stress accounts for a large variance in many dimensions of psychological wellbeing like Environmental Mastery (EM), Personal Growth (PG), Purpose in Life (PL), Positive Relations (PR), Self Acceptance (SA) and Autonomy (AU). The ability to find meaning and direction in life, and having goals and following them, despite setbacks is an important aspect of well-being. Psychological wellbeing is all about having self acceptance and striving for personal growth and having purpose in life. Perfectionism, stress, and dimensions of psychological well-being were studied in a sample of 265 college students. The results indicated that stress fully mediated the relations between socially prescribed perfectionism and three dimensions of psychological well-being, namely, autonomy, environmental mastery, and purpose in life (Chang, 2006). The results are in line with another study wherein stress was found to be single most significant predictor of psychological wellbeing and satisfaction among allied health professionals (Harris, Cumming \& Campbell, 2006). Garcia et al (2014) studied psychological wellbeing and harmony and found that harmony which is opposite to stress was significantly predicted by environmental mastery and self acceptance and in present study too, perceived stress has predicted maximum variance in both these dimensions. Various studies have shown that perfectionists worry and ruminate more about work than non-perfectionists making it difficult for perfectionists to switch off and relax after work, and this may negatively affect their work-life balance, health, and well-being (Flaxman, Ménard, Bond, \& Kinman, 2012; Mitchelson, 2009). In a study among Swedish adolescents, 


\section{Perceived Stress as Predictor of Psychological Well-being among Indian Youth}

psychological well-being, and especially the self-acceptance and environmental mastery dimensions were found to be strongly related to high levels of positive affect and life satisfaction (Garcia, 2011; Garcia \& Archer, 2012). Academic stress came out to be a strong predictor of well-being in medical school students. The results of this study suggested students who appraised school workload as stressful or threatening displayed lower levels of well-being (Rogers et al., 2012)

\section{CONCLUSION}

Despite these limitations, the present study makes a significant contribution to our understanding of perceived stress and its effects of psychological wellbeing among Indian youth. Results indicated that Perceived stress was found to be negatively correlated with psychological wellbeing. It becomes evident that Perceived Stress explains maximum variance in Positive Relations with others (PR), Environmental Mastery (EM) and Self Acceptance (SA) dimensions of psychological wellbeing. There have been, to the best of my knowledge, very few studies conducted that study the relationship between perceived stress and psychological wellbeing among Indian youth though both these variables have been studied extensively individually.

\section{Limitations and Future Studies}

The present study had many limitations. Though it was known that perceived stress would be affecting psychological wellbeing; the nature extent and relative contribution etc were not known and were exploratory in nature. Perceived stress explained a significant variance in psychological wellbeing, still more variables affecting psychological wellbeing need to be taken along with stress to explain psychological wellbeing better. The sample consisted of urban youth only and there is need to include rural population as well to be able to get a clear and more realistic picture of the whole relationship.

\section{Acknowledgments}

The author appreciates all those who participated in the study and helped to facilitate the research process.

\section{Conflict of Interests}

The author declared no conflict of interests.

\section{REFERENCES}

Cammata, C.D., \& Nagoshi, C.T. (1995). 'Stress, depression, irrational beliefs and alcohol use and problems in a college student sample.’ Alcoholism: Clinical and Empirical Research, 19, 142-146.

Chang, E.C. (2006). 'Perfectionism and Dimensions of Psychological Well-Being in a college Student Sample: A test of a stress-Mediation Model'. Journal of Social and Clinical Psychology, 25 (9), 1001-1022. DOI: 10.1521/jscp.2006.25.9.1001 


\section{Perceived Stress as Predictor of Psychological Well-being among Indian Youth}

Cohen, S., Kamarck, T. \& Mermelstein, R. (1983). 'A global measure of perceived stress'. Journal of Health and Social Behavior, 24, 386-396.

Flaxman, P.E., Ménard, J., Bond, F.W. \& Kinman, G. (2012). 'Academics' experiences of a respite from work: Effects of self-critical perfectionism and perseverative cognition on postrespite well-being’. Journal of Applied Psychology, 97, 854-865.

Garcia et al. (2014), 'The affective profiles, psychological well-being, and harmony: environmental mastery and self-acceptance predict the sense of a harmonious life'. PeerJ 2:e259; DOI 10.7717/peerj.259

Garcia, D. (2011). 'Adolescents' happiness: The role of the affective temperament model on memory and apprehension of events, subjective well-being, and psychological wellbeing'. Ph.D. Thesis, University of Gothenburg, Gothenburg.

Garcia, D., Archer, T. (2012). 'Adolescent life satisfaction and well-being'. Journal of Alternative Medicine Research, 4, 271-279.

Harris, L.M., Cumming, S.R., Campbell, A.J. (2006). 'Stress and psychological well-being among allied health professionals.’ Journal of Allied Health, Winter;35(4), 198-207.

Huppert, A. (2009). 'Psychological Well-being: Evidence Regarding its Causes and Consequences'. Applied Psychology: Health and Well-Being, 1 (2), 137-164.

Kadison, R. and DeGeronimo, T. Foy (2004). 'College of the overwhelmed: The campus mental health crisis and what to do about it'. CA: Jossey-Bass.

Lazarus, R. S., \& Folkman, S. (1984). Stress, appraisal, and coping. New York: Springer

Misra, R., \& McKean, M. (2000). 'College students' academic stress and its relation to their anxiety, time management, and leisure satisfaction'. American Journal of Health Studies, 16(1), 41-51.

Mitchelson, J.K. (2009). 'Seeking the perfect balance: Perfectionism and work-family conflict'. Journal of Occupational and Organizational Psychology, 82, 349-367.

National Youth Policy of India (2014). http://www.rgniyd.gov.in/sites/default/files/pdfs/scheme/nyp_2014.pdf

Rogers, M. E., Creed, P. A., \& Searle, J. (2012). 'Person and environmental factors associated with well-being in medical students'. Personality and Individual Differences, 52(4), 472- 477.

Ross, S.E., Niebling, B.C., \& Heckett, T.M. (1999). 'Sources of stress among college students'. College Student Journal, June 1999.

Ryff, CD. (1989). 'Happiness is everything, or is it? Explorations on the meaning of psychological well-being'. Journal of Personality and Social Psychology, 57,1069-1081.

Towbes, L. C, and L. H. Cohen. (1996). 'Chronic stress in the lives of college students: Scale development and prospective prediction of distress'. Journal of Youth and Adolescence, 25, 199-217.

How to cite this article: K Anand, Y Nagle (2016), Perceived Stress as Predictor of Psychological Well-being among Indian Youth, International Journal of Indian Psychology, Volume 3, Issue 4, No. 68, ISSN:2348-5396 (e), ISSN:2349-3429 (p), DIP:18.01.213/20160304, ISBN:978-1-365-39398-3 